\title{
Characterization of Hepatic Focal Lesions by Diffusion Tensor Imaging and How Far it Can Predict Post-Treatment Response?
}

\author{
NEHAD M.S. FOUDA, M.D.; KARIM M. ABDELHAMID, M.Sc. and NEHAL THARWAT, M.D. \\ The Department of Diagnostic Radiology, Faculty of Medicine, Mansoura University, Egypt
}

\begin{abstract}
Background: Liver diseases have been known to be a major health problem principally because of their world-wide distribution. Focal liver disease is a common diagnostic problem referred to radiologists for evaluation owing to its nonspecific clinical presentation and marked interobserver variation on clinical examination.

Aim of Study: The purpose of this study is to evaluate the role of diffusion tensor imaging in characterization of hepatic focal lesions and its value in post-treatment response.

Patients and Methods: This prospective study included 30 patients previously diagnosed to have hepatic focal lesions (HFLs) by their characteristic triphasic computed tomography (CT), dynamic magnetic resonance imaging (MRI) features and/or biopsy. The study included 43 lesions in 30 patients (16 benign lesions, 23 malignant lesions, and 4 treated malignant lesions). MRI with diffusion tensor imaging (DTI) was performed for all patients. Apparent diffusion coefficient (ADC) and fractional anisotropy (FA) values were evaluated for all lesions.
\end{abstract}

Results: There was a statistically significant difference in ADC values between the benign and malignant lesions $(p<0.001)$ and between the treated malignant and untreated malignant lesions $(p=0.002)$. There was a statistically significant difference in FA values between the benign and malignant lesions $(p<0.001)$ and between the treated malignant and untreated malignant lesions ( $p=0.004)$. The best cut-off ADC value to differentiate between benign and malignant lesions respectively was $>1.42 \times 10^{-3} \mathrm{~mm}^{2} / \mathrm{s}$ with $95.7 \%$ sensitivity and $82.8 \%$ specificity. The best cut-off ADC value to differentiate between treated malignant and malignant lesions respectively was $>1.65 \times 10^{-3} \mathrm{~mm}^{2} / \mathrm{s}$ with $97.8 \%$ sensitivity and $95.7 \%$ specificity. The best cut-off FA value to differentiate between malignant and benign lesions respectively was $>0.29$ with $95 \%$ sensitivity and $70 \%$ specificity. The best cut-off FA value to differentiate between treated malignant and untreated malignant lesions respectively was $<0.297$ with $100 \%$ sensitivity and $69.2 \%$ specificity.

Conclusion: Diffusion tensor imaging is an evolving technique that can be used to characterize different hepatic focal lesions either benign or malignant with significant

Correspondence to: Dr. Nehal Tharwat, E-Mail: nehaltharwat83@gmail.com additive value to dynamic contrast enhanced MRI examination. It can also be used to monitor treatment response. $\begin{aligned} \text { Key Words: } & \text { Diffusion tensor imaging - Hepatic focal lesions } \\ & \text { - Benign - Malignant. }\end{aligned}$

\section{Introduction}

LIVER diseases have been known to be a major health problem principally because of their worldwide distribution $[\mathbf{1 , 2}]$. Focal liver disease is a common diagnostic problem referred to radiologists for evaluation owing to its nonspecific clinical presentation and marked interobserver variation on clinical examination [3]

Hepatic focal lesions (HFLs) are classified into benign and malignant lesions. Hemangiomas are the commonest benign tumor while hepatocellular carcinoma (HCC) it is the commonest primary malignant liver tumor. HCC is the fifth most common cancer in the world and the third most frequent cause of death amongst oncological patients [4].

Modern operative techniques and local therapies such as radiofrequency (RF) ablation are effective methods to treat primary hepatic malignancies or liver metastases. Therefore, accurate determination

\footnotetext{
Abbreviations:

HFLs : Hepatic focal lesions.

CT : Computed tomography.

MRI : Magnetic resonance imaging.

DTI : Diffusion tensor imaging.

ADC : Apparent diffusion coefficient

FA : Fractional anisotropy.

HCC : Hepatocellular carcinoma.

RF : Radiofrequency.

USG : Ultrasonography.

DWI : Diffusion-weighted imaging.

TACE : Trans-arterial chemoembolization.

PPV : Positive predictive value.

NPV : Negative predictive value.
} 
of liver lesion count, and nature of the lesion are important [5].

HFLs are diagnosed using ultrasonography (USG) and/or computed tomography (CT). Triphasic CT has traditionally been considered the optimal diagnostic modality for HFLs. However, many limitations have been reported concerning triphasic CT study such as renal impairment, radiation dose, and inability to confirm the specific tissue properties of focal lesions in some cases, leading to indeterminate diagnosis.Conventional and dynamic contrast-enhanced magnetic resonance imaging (MRI) are ideal tools for obtaining anatomical details but cannot provide functional details for HFLs [6-9] .

Diffusion-weighted imaging (DWI) relates to the diffusion properties of water molecules and reveals the histopathological tissue characteristics. Malignant tissues with high cellularity, constriction of extracellular spaces and high density of hydrophobic membranes have usually more restricted diffusion making apparent diffusion coefficient (ADC) values lower [10,11] .

DWI provides limited information and does not provide information on tissue microstructure such as diffusion anisotropy. Diffusion tensor imaging (DTI) is MRI technique that reveals microstructural characteristics of biological tissue, which can detect the degree of diffusion in multiple directions by using additionalgradients [12]. Compared to three gradient-directions applied to DWI, at least six or more gradient directions for every section in DTI are needed to calculate the diffusion tensor providing additional information on anisotropy diffusion and total diffusion orientations [13]

The literature is especially sparse regarding the usage of DTI in characterization of different HFLs. DTI can achieve more precise ADC calculation. In addition, fractional anisotropy (FA) values obtained by DTI are useful in evaluating the scalar properties of the diffusion of extracellular water molecules. DTI has been widely applied in the brain. Recently, application of DTI in the liver for diagnosis and staging of fibrosis and inflammation, and distinguishing cyst,malignancy, and hemangioma has shown reasonably good success [14-17].

DTI does not require any exogenous contrast agent and can be safely performed in patients presenting contraindications for gadolinium contrast agents (patients suffering from severe renal deficiency or nephrogenic systemic fibrosis). Early clinical applications of DTI demonstrated the sensitivity of this technique to hepatic lesions com- pared to standard MRI especially in metastases and lesions of atypical enhancing pattern. Also, DTI might be effectively employed to determine the biopsy target [18].

Recently, a multiparametric MRI approach including dynamic contrast-enhanced MRI and other functional imaging tools such as DWI, MR elastography, and MR spectroscopy, has drawn a lot of attention as it allows not only morphologic evaluation but also functional evaluation of various liver diseases. This can help in maximizing specificity and accuracy of cross-sectional imaging and avoid unnecessary biopsies, which may portend a postprocedural morbidity of $2.0 \%$ to $4.8 \%$ and mortality of $0.05 \%$ [19]

This study tried to introduce FA values (in addition to ADC) as a new biomarker that can be used in the diagnostic work-up of liver lesions.

The aim of this study is to evaluate the role of DTI in characterization of HFLs previously diagnosed with their characteristic triphasic CT, dynamic MRI features and/or biopsy and its value in post treatment response.

\section{Patients and Methods}

This prospective single-institution study was approved by our institutional review board and written informed consent from all patients was obtained. This study was conducted during the period from January 2018 to January 2020. Thirty patients (16 males and 14 females; mean age 51.8 years) who were referred from oncology center and tropical medicine unit with HFLs diagnosed by theircharacteristic triphasic CT, dynamic MRI features and/or biopsywere enrolled in this study.

There were 21 cases with single lesion, 5 cases with 2 lesions and 4 cases with 3 lesions with total of 43 lesions. Among the 43 lesions there were 16 benign lesions (37.2\%), 23 malignant lesions $(53.5 \%)$ and 4 completely treated malignant lesions (HCC) $(9.3 \%)$. Regarding the type of the detected lesions, there were 12 haemangiomas $(27.9 \%), 3$ hydatid abscesses (7\%), 1 simple cyst (2.3\%), 12 HCC (27.9\%), 7 metastases (16.3\%), 2 cholangiocarcinomas (4.7\%), 1 dysplastic nodule $(2.3 \%)$, 1 epithelioid haemangioendothelioma $(2.3 \%)$ and 4 HCC treated by trans-arterial chemoembolization (TACE) and showed complete response (9.3\%).

All patients underwent MRI of the liver with DTI technique. We evaluated ADC and FA values of all lesions. 
Inclusion criteria: Patients diagnosed to have HFLs by different imaging modalities and characterized by triphasic CT or dynamic MRI and/or biopsy (if needed) and agreed to participate in the study.

\section{The gold standard diagnostic criteria of HFLs:}

- Haemangioma: Hyperintensity on heavy T2WI and the typical enhancement pattern seen in contrast-enhanced dynamic CT or MRI in the form of early peripheral nodular enhancement in arterial phase with centripetal progressive enhancement in portal and delayed phases [20].

- Hydatid abscesses: Unilocular or multilocular cysts with thin or thick walls and calcifications, usually with daughter cysts.On MRI, hydatid cyst appears low on T1-WI and high on T2-WI. Intraluminal debris presence may alter the signal intensity. Both fibrous capsule and internal septa tend to be hypointense on T2-WI and show enhancement in post gadolinium phase $[\mathbf{4 , 2 1}$.

- Simple cyst: Diagnosed according to their typical US, CT and MRI findings (thin smooth walls with no mural irregularity or nodularity or debris, hypodense non-enhancing on CT, nonenhancing on MRI with low T 1 and high T2 signal intensity) accompanied with follow-up evaluations of at least 12 months [17,22].

- HCC: On multiphasic contrast CT or MRI, diagnosed by arterial phase hyperenhancement, subsequent washout appearance in portal and delayed phases and delayed enhancing pseudocapsule. Additionally, HCC have the propensity to invade vascular structures, most commonly the portal vein [23].

- Metastases: The diagnosis of metastases was proven by means of biopsy or follow-up imaging examinations including CT and MRI during routine controls of patients with known primary tumors [17].

- Intrahepatic mass formingcholangiocarcino$m a$ : diagnosed on dynamic post-contrast scan by minor peripheral rim enhancement during both the arterial and portal venous phases, the central part frequently show gradual centripetal prolonged enhancement at delayed-phases with peripheral intrahepatic duct dilatation. Capsular retraction is highly suggestive of cholangiocarcinoma. Unlike HCC, cholangiocarcinoma only rarely forms a tumor thrombus. Also, cholangiocarcinomaappears hyperintense on T2-WI and central hypointensity in the tumor reflective of fibrosis may be seen $[21,24]$
- Dysplastic nodule: High-grade dysplastic nodules show iso to high signal on T1-WI and iso signal intensity on T2-WI. On dynamic post contrast study, high-grade nodules show early contrast enhancement in arterial phase and fade to isodensity or isointensity, butwithout washout on delayed phase (unlike HCC) [4]

- Epithelioid haemangioendothelioma: Typically seen as multiple lesions in a peripheral or subcapsular distribution, with a peripheral halo or target pattern of enhancement. Hepatic or portal veins or their branches may taper and terminate at or just within the edge of these lesions (lollipop sign) [25]

- HCC treated by TACE: The most important finding for a completely treated HCC is lack of internal enhancement. Treated masses usually demonstrate low signal intensity on T 1 and T2-WI unless there is hemorrhagic or proteinaceous debris, in which case there is high signal intensity on T1WI. In such instances, subtraction imaging help to identify subtle areas of arterial hyperenhancement indicative of viable tumor [26].

Exclusion criteria: General contra-indication for MRI scan (cardiac pacemaker, metallic implant), bad general condition and uncooperative patients who were unstable on machine table or cannot hold their breath.

\section{MR imaging technique:}

MRI was performed on high field system (1.5 Tesla) magnet units (Philips Ingenia) using a phased array coil to cover the whole liver. Patients were asked to avoid deep breathing during examination. Conventional MRI and DTI studies were performed. First; detection andlocalization of focal lesions were performed; second, the DTI with ADC and FA maps were performed.

MR Protocol: $\mathrm{T} 1 \mathrm{WI}(\mathrm{TR}=112 \mathrm{msec}, \mathrm{TE}=$ $4.8 \mathrm{msec}$, matrix 179x320, slice thickness 7-8mm, slice gap 1-2mm and FOV 300-400mm). T2WI (TR $1800 \mathrm{msec}, \mathrm{TE}=80 \mathrm{msec}$, matrix 200x240, slice thickness 7-8mm, slice gap 1-2mm and FOV 300$400 \mathrm{~mm}$ ). T2 SPAIR (Spectral Attenuated Inversion Recovery) fatsuppression sequence: TR $>400 \mathrm{msec}$, $\mathrm{TE}=80 \mathrm{msec}$, matrix $204 \times 384$, slice thickness 7$8 \mathrm{~mm}$, slice gap 1-2mm and FOV300-400mm.

\section{Diffusion tensor study:}

An axial non-breathhold, single-shot gradient echo planar DTI sequence covering the whole liver was acquired using the following parameters: Acquisition time, 3:04 (min:sec), TE=94msec, TR $>2371 \mathrm{msec}$, matrix 256x160, slice thickness 8mm, slice gap $1 \mathrm{~mm}$, with different $b$-values $(b=0,500$, 
$800 \& 1000 \mathrm{~s} / \mathrm{mm}^{2}$ ) with six diffusion directions applied.

Image analysis: ADC and FA maps were processed using secondary work station provided by the vendor (Phillips Advantage windows workstation with functional tool software). Analysis of ADC and FA values of HFLs was done by an expert radiologist (15 years' experience in hepatic imaging, 8 years' experience in DTI analysis) by applying regions of interest (ROIs) in each lesion on ADC and FA maps. In cystic lesions, ROIs were placed within the margins of the lesions.

\section{Statistical analysis of data:}

The collected data were coded, processed and analyzed using the SPSS (Statistical Package for Social Sciences) version 22 for Windows ${ }^{\circledR}$ (IBM SPSS Inc, Chicago, IL, USA). Data were tested for normal distribution using the Shapiro Walk test. Qualitative data were represented as frequencies and relative percentages. Quantitative data were expressed as median (minimum \& maximum). Kruskal Wallis test was used to compare non parametric data between more than 2 groups with paired comparison by Mann Whitney U test. Receiver operator characteristic (ROC) curve was tested to calculate the diagnostic ability of quantitative variable in prediction of categorical outcome. Significance test results are quoted as two-tailed probabilities. For all the above-mentioned tests, the level of significance was tested, expressed as the probability of ( $p$-value) and the results were considered significant if the $p$-value is $\leq 0.05$ and highly significant if the $p$-value $<0.001$.

\section{Results}

This study included 30 patients with mean age of $51.8 \pm 12.7$ years and age range between 23 and 73 years. Among the patients there were 16 males $(53.3 \%)$ and 14 females $(46.7 \%)$.

The mean ADC value of the different lesions in our study was $1.60 \pm 0.63 \times 10^{-3} \mathrm{~mm}^{2} / \mathrm{s}$ and the median value was $1.35 \times 10^{-3} \mathrm{~mm}^{2} / \mathrm{s}$ with range between 0.87 and $3.63 \times 10^{-3} \mathrm{~mm}^{2} / \mathrm{s}$. The mean value of FA of the different lesions in our study was $0.33 \pm 0.14$ and the median value was 0.33 with range between 0.08 and 0.74 .

The median and minimum-maximum ADC and FA values of benign, malignant, and treated malignant (HCC) lesions are shown in Table (1). There was a statistically significant difference in ADC value between the benign and malignant lesions $(p<0.001)$, between the treated HCC and untreated malignant lesions $(p=0.002)$, but there was no statistically significant difference noted between the benign lesions and treated HCC $(p=0.705)$. Also, there was a statistically significant difference in FA values between the benign and malignant lesions $(p<0.001)$ and between treated HCC and untreated malignant lesions $(p=0.004)$, but there was no statistically significant difference between the benign lesions and treated HCC $(p=0.345)$ (Table 1) (Figs. 1,2).

Table (1): ADC and FA values of benign, malignant and treated HCC lesions.

\begin{tabular}{|c|c|c|c|c|}
\hline & $\begin{array}{l}\text { Benign } \\
(n=16)\end{array}$ & $\begin{array}{l}\text { Malignant } \\
(\mathrm{n}=23)\end{array}$ & $\begin{array}{l}\text { Treated HCC } \\
\quad(n=4)\end{array}$ & $\begin{array}{c}\text { Test of } \\
\text { significance }\end{array}$ \\
\hline \multicolumn{5}{|l|}{$A D C:$} \\
\hline Median & 2.152 & 1.212 & 2.024 & \multirow{4}{*}{$\begin{array}{l}\mathrm{KW} \chi^{2}=25.65 \\
p<0.001 *\end{array}$} \\
\hline Minimum-Maximum & $1.21-3.63$ & $0.87-1.46$ & $1.86-2.17$ & \\
\hline$p_{1}$ & & $<0.001^{*}$ & 0.705 & \\
\hline$p_{2}$ & & & $0.002 *$ & \\
\hline \multicolumn{5}{|l|}{$F A:$} \\
\hline Median & 0.211 & 0.381 & 0.2815 & \multirow{4}{*}{$\begin{array}{l}\mathrm{KW} \chi^{2}=16.34 \\
p<0.001 *\end{array}$} \\
\hline Minimum-Maximum & $0.08-0.43$ & $0.17-0.74$ & $0.25-0.29$ & \\
\hline$p_{1}$ & & $<0.001 *$ & 0.345 & \\
\hline$p_{2}$ & & & $0.004 *$ & \\
\hline $\begin{array}{l}\text { Non parametric data expres } \\
\text { KW } \chi=\text { Kruskal Wallis Te } \\
\text { Chi-Square. } \\
\text { Mann-Whitney U. }\end{array}$ & edian, minir & & $\begin{array}{l}p \text { : Probability. } \\
*: \text { Statistically signific } \\
\text { p1: Significance in rel } \\
\text { p2: Significance in rel }\end{array}$ & $\begin{array}{l}.05) \text {. } \\
\text { benign group. } \\
\text { malignant group. }\end{array}$ \\
\hline
\end{tabular}



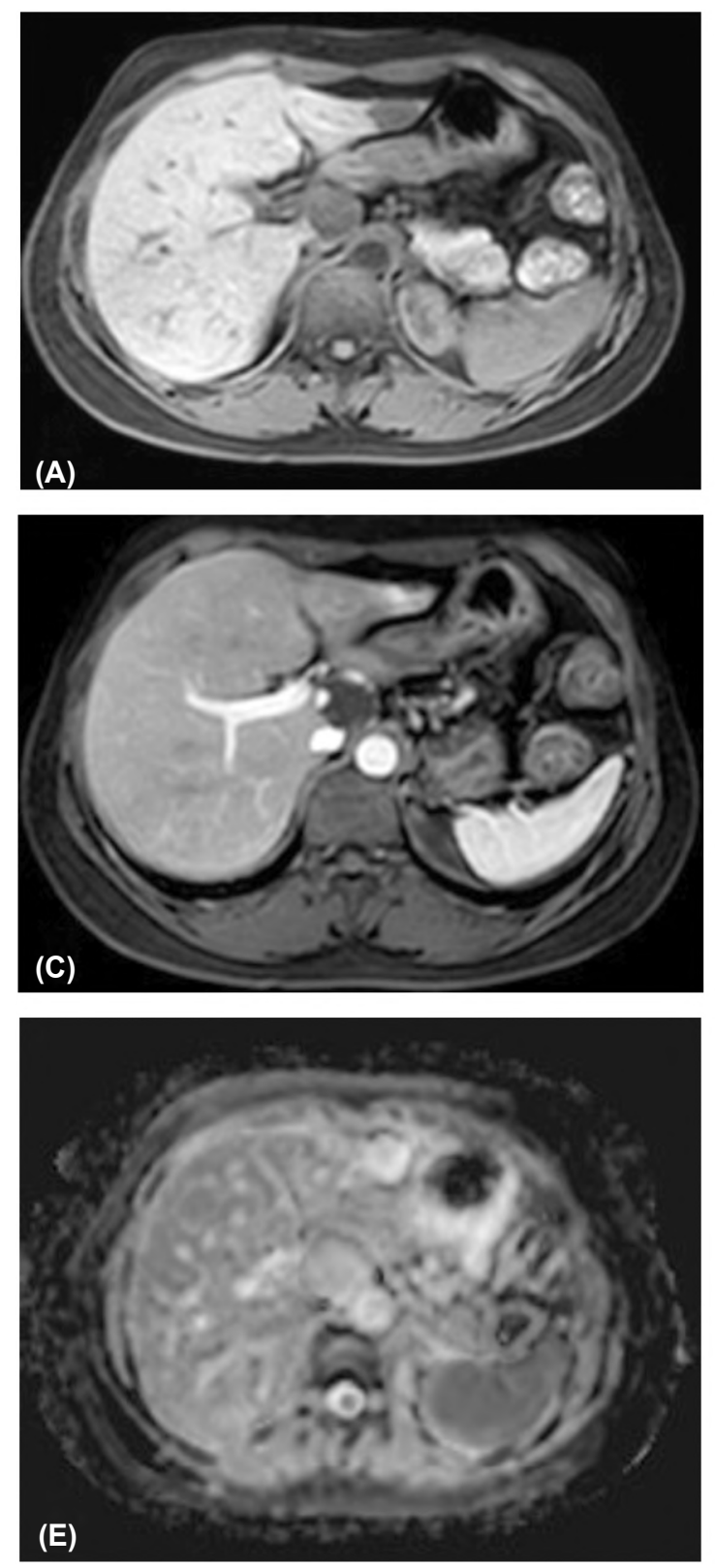
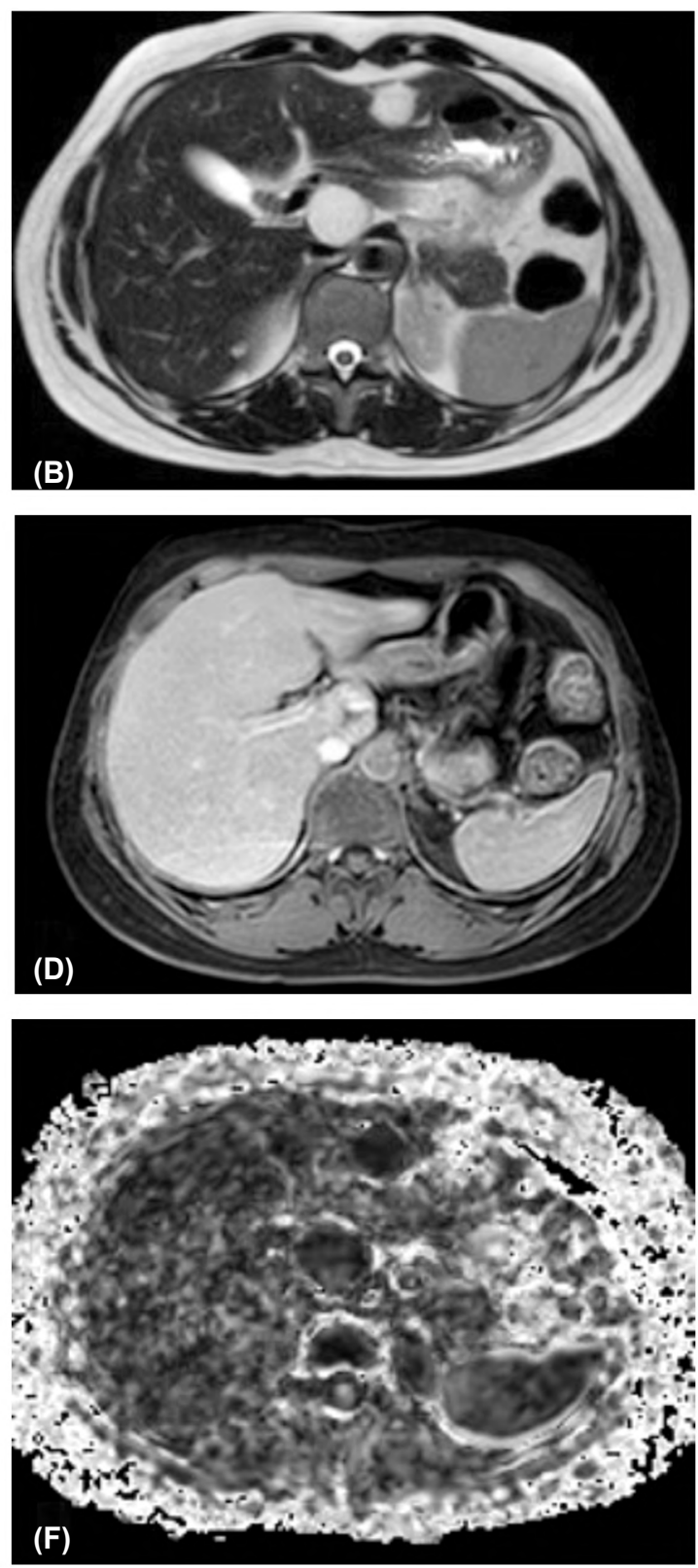

Fig. (1): Female patient 37 years old with 2 echogenic HFLs seen in segment I and III detected on ultrasound examination and diagnosed as hemangiomas by their typical closing iris pattern on dynamic MRI study, the lesions show low T1 SI (A) and bright T2 SI (B), progressive fill in is seen on arterial and delayed phases of dynamic study (C, D). DTI was performed, the 2 lesions show mean ADC value of 3.1 and $2.8 \times 10^{-3} \mathrm{~mm}^{2} / \mathrm{s}$, mean FA value of 0.24 and 0.26 that cope with benign nature (E, F) show ADC and FA maps respectively.

In our study, the best cut-off ADC value to differentiate between benign and malignant lesions respectively was $>1.42 \times 10^{-3} \mathrm{~mm}^{2} / \mathrm{s}$ with $95.7 \%$ sensitivity, $82.8 \%$ specificity, $96.4 \%$ positive predictive value (PPV), $94.3 \%$ negative predictive value (NPV) and total accuracy of $88.6 \%$. This value was considered statistically significant ( $p=0.001$ ) (Fig. 3). The best cut-off ADC value to differentiate between treated HCC and untreated malignant lesions respectively was $>1.65 \times 10^{-3}$ $\mathrm{mm}^{2} / \mathrm{s}$ with $97.8 \%$ sensitivity, $95.7 \%$ specificity,
96.4\% PPV, 94.3\% NPV and total accuracy of $95.2 \%$. This value was considered statistically significant $(p<0.001)$.

In our study, the best cut-off FA value to differentiate between malignant and benign lesions respectively was $>0.29$ with $95 \%$ sensitivity, $70 \%$ specificity, 92\% PPV, 82\% NPV and total accuracy of $85 \%$. This value was considered statistically significant ( $p=0.001$ ) (Fig. 4). The best cut-off FA value to differentiate between treated malignant and untreated malignant lesions respectively was 
$<0.297$ with $100 \%$ sensitivity, $69.2 \%$ specificity, $80 \% \mathrm{PPV}, 95.7 \% \mathrm{NPV}$ and total accuracy of $96.3 \%$.
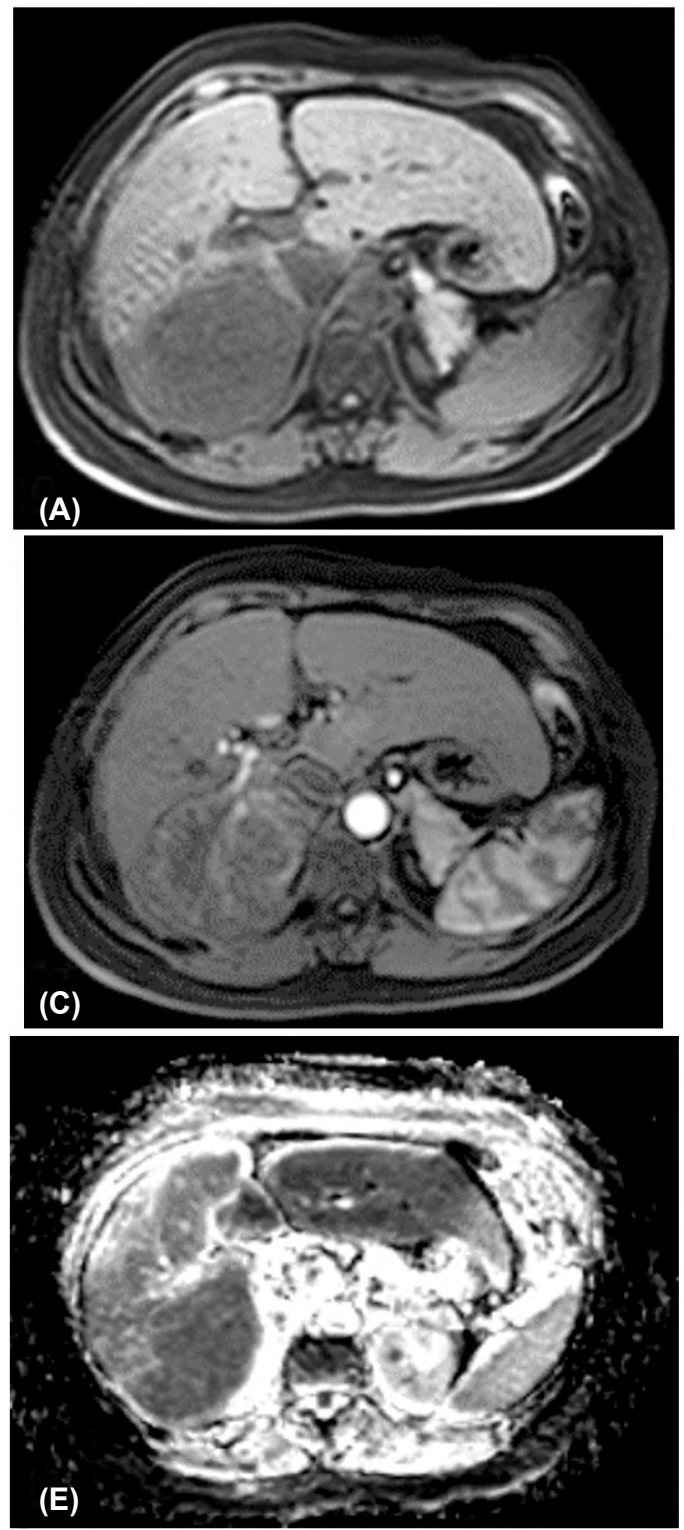

Yet, this value was considered statistically nonsignificant $(p=0.181)$.
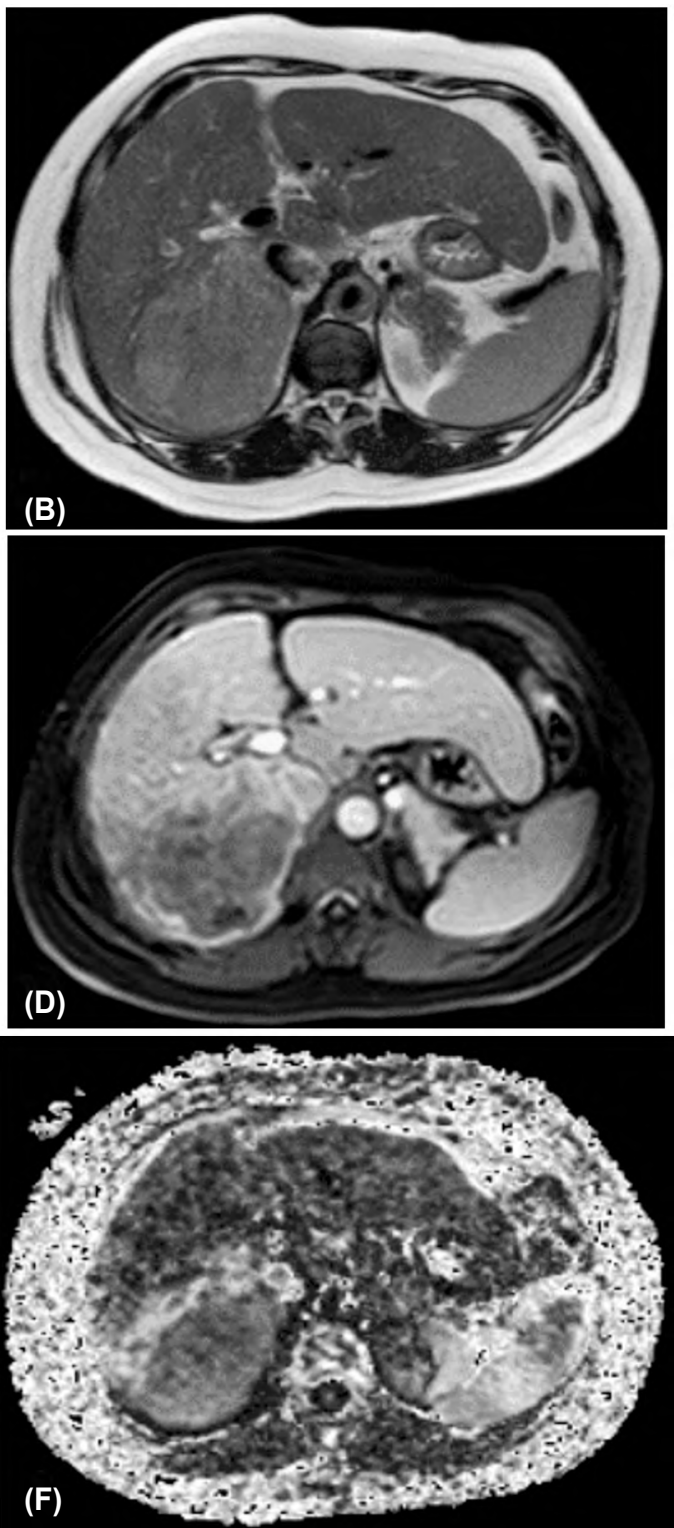

Fig. (2): Female patient 56 years old with cirrhotic liver secondary to chronic hepatitis $\mathrm{C}$ infection diagnosed to have HCC in segment VII on dynamic MRI displaying low T1-SI (A) and relatively high T2-SI (B) with heterogenous enhancement in arterial phase (C) with wash-out in portal and delayed phases (D). DTI was performed, the lesion shows ADC value of $0.8 \times 10^{-3} \mathrm{~mm} / \mathrm{s}$ and FA value of 0.39 suggestive of malignant nature $(\mathrm{E}, \mathrm{F})$ show ADC and FA maps respectively.

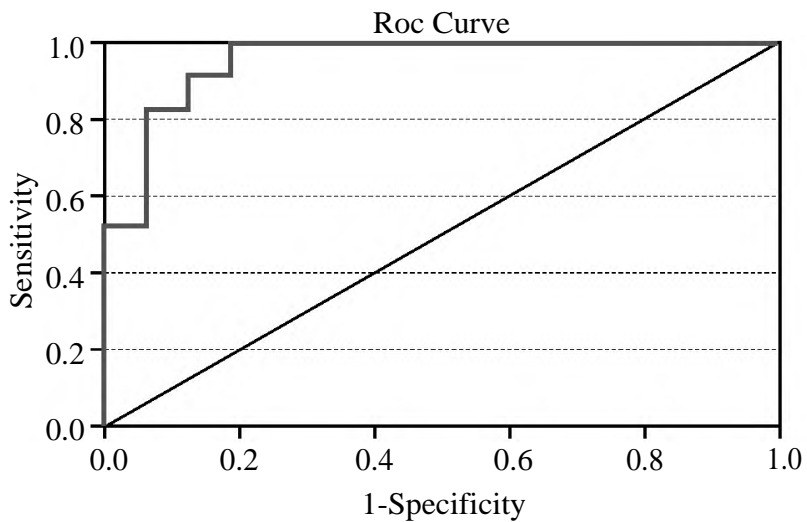

Fig. (3): ROC curve for ADC cut-off value in differentiation between benign and malignant lesions.

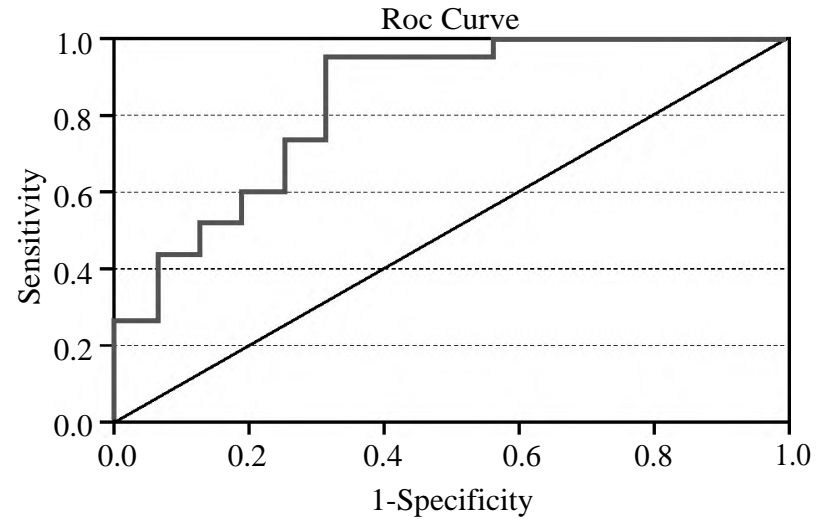

Fig. (4): ROC curve for cut-off FA value in differentiation between benign and malignant lesions. 


\section{Discussion}

MRI is a preferred technique when further characterization of HFLs is needed. Lesion morphology, signal intensity, and contrast enhancement pattern are taken into consideration when characterizing masses with MRI. Yet, there can still be difficulties in the differentiation of benign and malignant lesions [27]. DW-MRI has proven a great and growing role in diagnosing hepatic pathology compared to other MRI techniques. Indeed, DWMRI and quantitative ADC measurements is a fast and completely non-invasive technique that does not require contrast agent administration with possibility of better differentiation between benign and malignant lesions [28,29]

By using DTI, it is possible to obtain not only the ADC values but also the FA values that may also provide useful information regarding HFLs. The hypothesis is that the diffusion in malignant lesions should be more restricted and more anisotropic when compared to benign lesions resulting in outcomes as lower ADC values and higher FA values for malignant lesions [17].

In our study the most common malignant lesion was HCC (27.9\%), the most common benign lesion washemangioma (27.9\%). This came in agreement with Abdel Kader et al., who declared that out of 312 lesions in his study, HCC was the most common malignant lesion (171/312), hemangioma was the commonest benign lesion(65/312) [30]. Also, nearly similar results were obtained in the study done by Debees et al., as they stated that among studied 27 malignant lesions; HCC came first $(15 / 27)[31]$

In this study, the median $\mathrm{ADC}$ value of benign lesions was $2.152 \times 10^{-3} \mathrm{~mm}^{2} / \mathrm{s}$, for malignant lesions $1.212 \times 10^{-3} \mathrm{~mm}^{2} / \mathrm{s}$ and for treated $\mathrm{HCC}$ was $2.024 \times 10^{-3} \mathrm{~mm}^{2} / \mathrm{s}$. There was a statistically significant difference in ADC value between the benign and malignant lesions $(p<0.001)$, between the treated HCC and untreated malignant lesions $(p=0.002)$, but there was no statistically significant difference noted between the benign and treated HCC lesions $(p=0.705)$.

Our study came in agreement with Javadrashid et al., who found that the mean ADC value for benign lesions $\left(1.58 \pm 0.35 \times 10^{-3} \mathrm{~mm}^{2} / \mathrm{s}\right)$ was significantly higher than malignant lesions $(0.87 \pm$ $\left.0.16 \times 10^{-3} \mathrm{~mm}^{2} / \mathrm{s}\right)$ with $(p=0.001)[32]$. Also, Jain et al., stated that the mean ADC value for benign lesions was $1.678 \times 10^{-3} \mathrm{~mm}^{2} / \mathrm{s}$, and for malignant lesions was $1.097 \times 10^{-3} \mathrm{~mm}^{2} / \mathrm{s}$, with statistically significant difference in-between $(p<0.001)$ [33]
El-Refaei and colleagues found high level of mean $\mathrm{ADC}$ in simple cyst and hemangioma more than that of metastasis and HCC, with highly statistically significant difference $(p=0.001)$ in mean ADC between benign and malignant lesions [7]. This difference in ADC values or cut-off ADC values between mentioned studies may be due to the use of variable $b$-values as diffusion gradients.

Our study has reported that there was statistically significant difference in the median ADC value between the treated malignant $(\mathrm{HCC})$ and untreated malignant lesions ( $p=0.002)$, but there was no statistically significant difference noted between the benign and treated malignant lesions $(p=0.705)$.

Increased ADC values in tumours after treatment generally show positive correlation with tumour response. The increase of ADC values as a response to treatment occurs earlier than size change in focal hepatic tumours. Correlation between ADC values and tumour response was mainly studied with colorectal metastases treated with chemotherapy and HCCs treated with chemoembolization therapy [34]

This came in agreement with Abduljaleel et al., who showed that ablation zones can be differentiated from surrounding liver parenchyma visually in the DWI and by means of ADC maps in all patients. They reported that the mean ADC of the well ablated lesion was $1.4 \times 10^{-3} \mathrm{~mm}^{2} / \mathrm{s}$ and of the residual lesion $0.8 \times 10^{-3} \mathrm{~mm}^{2} / \mathrm{s}$ with significant statistical difference between the residual viable tumor and the well ablated lesions [35].

This also came in accordance with Tantawy and Mohamed who found that ADC values were significantly higher in lesions that responded toTACE or radio frequency ablation (RFA) than in non-responding lesions. The mean ADC of the lesions before treatment was $1.27 \pm 0.25 \times 10^{-3}$ $\mathrm{mm}^{2} / \mathrm{s}$, and increased after treatment in responding lesions to reach $1.57 \pm 0.22 \times 10^{-3} \mathrm{~mm}^{2} / \mathrm{s}$ with a statistically significant difference $(p=0.002)$ [34].

This also agreed with Lo et al., who found that an ADC change of $\geq 25 \%$ within 6 months poststereotactic ablative radiotherapy (SABR) was an independent predictor of sustained HCC tumor control. The ADC values pre- and post-SABR were $1.43 \pm 0.28 \times 10^{-3} \mathrm{~mm}^{2} / \mathrm{s}$ and $1.72 \pm 0.34 \times 10^{-3}$ $\mathrm{mm}^{2} / \mathrm{s}$ respectively $(p<0.001)[36]$. This indicated that the ADC values could be established as a monitoring tool to assess the response of malignant lesions for treatment. 
In this study, the best cut-off ADC value to differentiate between benign and malignant lesions respectively was $>1.42 \times 10^{-3} \mathrm{~mm}^{2} / \mathrm{s}$ with $95.7 \%$ sensitivity, $82.8 \%$ specificity, $96.4 \%$ PPV, $94.3 \%$ NPV and total accuracy of $88.6 \%$.

This came in agreement with Madhu et al., who found that the best ADC cut-off value to differentiate between benign and malignant HFLs was $1.431 \times 10^{-3} \mathrm{~mm}^{2} / \mathrm{swith}$ sensitivity of $87.5 \%$, specificity of $71 \%$, PPV of $79.5 \%$ and NPV of 81.5\% [37]. Also, Jain et al., defined an ADC value of $1.26 \times 10^{-3} \mathrm{~mm}^{2} / \mathrm{s}$ to be the best available cutoff value for differentiating benign and malignant lesions, achieving sensitivity and specificity of $92 \%$ and $80 \%$, respectively [33]

Within the same context, Hasan et al., reported that by using ADC cut-off of $1.6 \times 10^{-3} \mathrm{~mm}^{2} / \mathrm{s}$ led to the highest accuracy for the differentiation of malignant and benign liver lesions $(86 \%)$ with a sensitivity of $100 \%$ and specificity of $68 \%$ for malignant lesions. Its strength was in its $100 \%$ NPV where ADC values above $1.6 \times 10^{-3} \mathrm{~mm}^{2} / \mathrm{s}$ exclude the malignant lesions [38].

However, ADC fails to define the characteristics of diffusion in anisotropic environments. Anisotropic properties of tissues can be evaluated using DTI, which allows the analysis of diffusion along multiple directions by employing additional gradients. By using DTI, in addition to ADC values, FA values can be calculated. FA values show the fraction of anisotropic diffusion to total diffusion. Higher FA indicated higher tumor cell density and higher malignant potential $[\mathbf{1 5 , 1 7 ]}$.

In this study, the median FA value of the benign lesions was 0.211 , for malignant lesions 0.381 and for treated malignant lesions (HCC) was 0.2815. There was a statistically significant difference in FA values between the benign and malignant lesions $(p<0.001)$, and between treated malignant and untreated malignant lesions $(p=0.004)$, but there was no statistically significant difference between the benign and treated malignant lesions $(p=0.345)$.

This came in agreement with Li et al., who found that the mean FA value of HCC lesions $(0.42$ \pm 0.11 ) was significantly higher than that of normal liver parenchyma $(0.32 \pm 0.10)(p=0.004)$ [15]. This also came in accordance with Erturk et al., as they showed that the mean FA values of cysts, hemangiomas, and metastases were $0.2 \pm 0.05,0.37 \pm 0.1$ and $0.46 \pm 0.1$, respectively. The differences in FA values of cysts and metastases and of cysts and hemangiomas were statistically significant $(p<0.01)$. On the other hand, the difference between metastases and hemangiomas was not significant $(p=0.88)[17]$.

In this study, the best cut-off FA value to differentiate between malignant and benign lesions respectively was $>0.29$ with $95 \%$ sensitivity, $70 \%$ specificity, 92\% PPV, 82\% NPV and total accuracy of $85 \%$. This value was considered statistically significant $(p=0.001)$. Similar results were obtained by Erturk et al.who reported that in distinguishing metastases (malignant lesions) from cysts and hemangiomas (benign lesions) using FA value of 0.31 as the cut-off value, the sensitivity was $56.2 \%$ and the specificity was $80 \%$ [17].

As regard usage of FA values to monitor the response of malignant lesions for treatment, there was lack of researches assessing FA changes in patients with malignant HFLs after treatment. However, Abdel Razek et al., in a study about breast cancer found higher FA values in tumor recurrence than post-operative changes in patients with breast conserving surgery with statistically significant difference $(p=0.003)$ that matched with our results [39]. On the other hand, D'Arco et al., in a study concerning pediatric brain tumour response stated that anisotropy within the matrix of tumour tissue is initially low making the evaluation or follow-up of diffusion anisotropy within tumours after treatment of little benefit [40]

The limitation of this study was the small number of patients and treated malignant lesions included in the study.

\section{Conclusion:}

MRI with DTI is an effective non-invasive tool with significant additive value to dynamic contrast enhanced MRI examination in detection and characterization of different HFLs due to its ease of acquisition and ability to obtain functional information in absence of intravenous contrast, especially in patients with abnormal renal function. It also may help in characterization of lesions with non-specific enhancing pattern. It can be used as a monitoring tool for assessment of treatment response in malignant hepatic lesions. Further studies should be performed including larger number of patients from more thanone center.

\section{References}

1- WANG F.S., FAN J.G., ZHANG Z., GAO B. and WANG H.Y.: The global burden of liver disease: The major impact of China. Hepatology, 60: 2099-2108, 2014.

2- SEPANLOU S.G., SAFIRI S., BISIGNANO C., IKUTA K.S., MERAT S., SABERIFIROOZI M., et al.: The global, regional, and national burden of cirrhosis by cause in 195 countries and territories, 1990-2017: A systematic analysis 
for the global burden of disease study 2017. Lancet Gastroenterol. Hepatol., 5: 245-266, 2020.

3- SHENOY-BHANGLE A., BALIYAN V., KORDBACHEH H., GUIMARAES A.R. and KAMBADAKONE A.: Diffusion weighted magnetic resonance imaging of liver: Principles, clinical applications and recent updates. World journal of hepatology, 9: 1081-1091, 2017.

4- MATOS A.P., VELLONI F., RAMALHO M., ALOBAIDY M., RAJAPAKSHA A. and SEMELKA R.C.: Focal liver lesions: Practical magnetic resonance imaging approach. World journal of hepatology, 7: 1987-2008, 2015.

5- JOHNSON B.W. and WRIGHT G.P.: Regional therapies for the treatment of primary and metastatic hepatic tumors: A disease-based review of techniques and critical appraisal of current evidence. The American Journal of Surgery, 217: 541-545, 2019.

6- SAWHNEY S., WILSON S.R.: Can ultrasound with contrast enhancement replace nonenhanced computed tomography scans in patients with contraindication to computed tomography contrast agents? Ultrasound quarterly, 33: 125-132, 2017.

7- EL-REFAEI M.A., YOUSEF M.A., REFAAT M.M., HELMY I.M.: Diffusion-weighted MRI: Role indiagnosing hepatic focal lesions. Journal of Medicine in Scientific Research, 2: 16-23, 2019.

8- ABD EL HAK M.T., METWALLY N.A. and ABDRABO A.S.: Role of diffusion-weighted MRI in hepatocellular carcinoma patients following transarterial chemoembolization (TACE). The Egyptian Journal of Medicine, 76: 3380-3391, 2019.

9- AN J.Y., PEÑA M.A., CUNHA G.M., BOOKER M.T., TAOULI B., YOKOO T., et al.: Abbreviated MRI for hepatocellular carcinoma screening and surveillance. RadioGraphics, 40: 1916-1931, 2020.

10- Ni P., Lin Y., Zhong Q., Chen Z., Sandrasegaran K., Lin C.: Technical advancements and protocol optimization of diffusion-weighted imaging (DWI) in liver. Abdominal Radiology, 41: 189-202, 2016.

11- CALISTRI L., CASTELLANI A., MATTEUZZI B., MAZZONI E., PRADELLA S. and COLAGRANDE S. Focal liver lesions classification and characterization: What value do DWI and ADC have? Journal of computer assisted tomography, 40: 701-708, 2016.

12- LERNER A., MOGENSEN M.A., KIM P.E., SHIROISHI M.S., HWANG D.H. and LAW M.: Clinical applications of diffusion tensor imaging. World neurosurgery, 82: 96109,2014

13- RAZEK A.A.K.A.: Diffusion tensor imaging in differentiation of residual head and neck squamous cell carcinoma from post-radiation changes. Magn Reson Imaging, 54: 84-89, 2018.

14- ABDEL RAZEK A.A.K., EL-SEROUGY L., ABDELSALAM M., GABALLA G. and TALAAT M.: Differentiation of primary central nervous system lymphoma from glioblastoma: Quantitative analysis using arterial spin labeling and diffusion tensor imaging. World Neurosurg, 123: e303-e309, 2019.

15- LI X., LIANG Q., ZHUANG L., ZHANG X., CHEN T., LI L., et al.: Preliminary study of MR diffusion tensor imaging of the liver for the diagnosis of hepatocellular carcinoma. PloS one, 10: e0135568, 2015.
16- WONG O.L., LEUNG T.W., LO G.G., YUAN J., LI W.W. and NOSEWORTHY M.D.: Intrasession and intersession repeatability of diffusion tensor imaging in healthy human liver. Journal of computer assisted tomography, 41: 578$585,2017$.

17- ERTURK S.M., ICHIKAWA T., KAYA E., YAPICI O., OZEL A., MAHMUTOGLU A.S., et al.: Diffusion tensor imaging of cysts, hemangiomas, and metastases of the liver. Acta radiologica, 55: 654-660, 2014.

18- OUSSOUS S.A., BOUJRAF S. and KAMAOUI I.: Assessment of the focal hepatic lesions using diffusion tensor magnetic resonance imaging. Journal of medical signals and sensors, 6: 99-105, 2016.

19- MORANA G., GRAZIOLI L., KIRCHIN M.A., BONDIONI M.P., FACCIOLI N., GUARISE A., et al.: Solid hypervascular liver lesions: Accurate identification of true benign lesions on enhanced dynamic and hepatobiliary phase magnetic resonance imaging after gadobenate dimeglumine administration. Invest Radiol., 46: 225-239, 2011.

20- TAMADA T., ITO K., YAMAMOTO A., SONE T., KANKI A., TANAKA F., et al.: Hepatic hemangiomas: Evaluation of enhancement patterns at dynamic MRI with gadoxetate disodium. AJR, 196: 824-830, 2011.

21- SCHIMA W., KOH D. and BARON R.: Focal Liver Lesions. In: Hodler J., Kubik-Huch R.A., von Schulthess G.K. (eds) Diseases of the Abdomen and Pelvis 20182021 Diagnostic Imaging-IDKD Book. Springer, 173196, 2018

22- MAVILIA M.G., PAKALA T., MOLINA M. and WU G.Y.: Differentiating cystic liver lesions: Areview of imaging modalities, diagnosis and management. J. Clin. Transl. Hepatol., 6: 208-216, 2018.

23- ROBERTS L.R., SIRLIN C.B., ZAIEM F., ALMASRI J., PROKOP L.J., HEIMBACH J.K., et al.: Imaging for the diagnosis of hepatocellular carcinoma: Asystematic review and meta-analysis. Hepatology, 67: 401-421, 2018

24- CHUNG Y.E., KIM M.J., PARK Y.N., CHOI J.Y., PYO J.Y., KIM Y.C., et al.: Varying appearances of cholangiocarcinoma: Radiologic pathologic correlation. RadioGraphics, 29: 683-700, 2009.

25- LIN J., JI Y.: CT and MRI diagnosis of hepatic epithelioid hemangioendothelioma. Hepatobiliary Pancreat Dis. Int., 9: $154-8,2010$.

26- MENDIRATTA-LALA M., MASCH W.R., SHAMPAIN K., ZHANG A., JO A.S., MOORMAN S., et al.: MRI assessment of hepatocellular carcinoma after local-regional therapy: Acomprehensive review. Radiology: Imaging Cancer, 2: e190024, 2020.

27- LEBERT P., ADENS-FAUQUEMBERGUE M., AZAHAF M., GNEMMI V., BEHAL H., LUCIANI A., et al.: MRI for characterization of benign hepatocellular tumors on hepatobiliary phase: The added value of in-phase imaging and lesion-to-liver visual signal intensity ratio. European radiology, 29: 5742-5751, 2019.

28- METWALLY L.I., EL TATAWY S.A. and ZAYED N.A.: Cirrhosis-associated liver nodules in Egyptian patients: Correlation of histopathologic and MRI with diffusion findings. Kasr Al Ainy Medical Journal, 25: 7-21, 2019. 
29- FILO S., SHTANGEL O., SALAMON N., KOL A., WEISINGER B., SHIFMAN S., et al.: Disentangling molecular alterations from water-content changes in the aging human brain using quantitative MRI. Nature communications, 10: 1-16, 2019.

30- ABDEL KADER M., ABDEL GHANI H.S., SAAD Z. and ABDALLA N.H.: To what extent the DW-MRI and ADC value can be used in assessment of hepatic focal lesions in cirrhotic patients. Egyptian Journal of Radiology and Nuclear Medicine, 48: 825-837, 2017.

31- DEBEES N.L., SHERIF M.F., YONES S.G. and AHMAD A.H.: Assessment of hepatic focal lesions on top of cirrhotic liver using dynamic and diffusion weighted magnetic resonance imaging. The Egyptian Journal of Radiology and Nuclear Medicine, 47: 1221-1230, 2016.

32- JAVADRASHID R., OLYAEI A.S., TARZAMNI M.K., RAZZAGHI R., JALILI J., HASHEMZADEH S., et al.: The diagnostic value of diffusion-weighted imaging in differentiating benign from malignant hepatic lesions. Egyptian Liver Journal, 10: 1-9, 2020.

33- JAIN T.P., TER-KAN W., EDWARD S., FERNON H. and NAIDER R.K.: Evaluation of ADC ratio on liver MRI diffusion to discriminate benign versus malignant solid liver lesions. European journal of radiology, 5: 209-214, 2018.

34- TANTAWY H.I. and MOHAMED F.F.: Diagnostic value of apparent diffusion coefficient (ADC) in evaluating hepatocellular carcinomas post trans-catheter arterial chemoembolization and radiofrequency ablation. The Egyptian Journal of Radiology and Nuclear Medicine, 47: 699-706, 2016.
35- ABDULJALEEL J.K., HAMID H.F. and SOLIMAN A.H.: Role of diffusion weighted MR imaging in assessment of hepatocellular carcinoma after radiofrequency ablation. The Egyptian Journal of Hospital Medicine, 71: 3229. $3231,2018$.

36- LO C., HUANG W., HSIANG C., LEE M., LIN C., YANG J., et al.: Prognostic significance of apparent diffusioncoefficient in hepatocellular carcinoma patients treated with stereotactic ablative radiotherapy. Scientific reports, 9: $1-8,2019$.

37- MADHU S.D., JAIPAL R., POOJA and RAGHURAM P.: Role of DWI in detection and characterization of focal liver lesions. International Journal of Anatomy, Radiology and Surgery, 5: 59-66, 2016.

38- HASAN N.M., ZAKI K.F., ALAM-ELDEEN M.H. and HAMEDI H.R.: Benign versus malignant focal liver lesions: Diagnostic value of qualitative and quantitative diffusion weighted MR imaging. The Egyptian Journal of Radiology and Nuclear Medicine, 47: 1211-1220, 2016.

39- ABDEL RAZEK A.A., ZAKY M., BAYOUMI D., TAMAN S., ABDELWAHAB K. and ALGHANDOUR R.: Diffusion tensor imaging parameters in differentiation recurrent breast cancer from post-operative changes in patients with breast-conserving surgery. European Journal of Radiology, 111: 76-80, 2019.

40- D'ARCO F., MANKAD K., NELSON M. and TAMRAZI B.: Neuro-oncology: Assessing response in paediatric brain tumours. In: Stephan D., Kieran M. (eds) Imaging in pediatric oncology. Springer, 171-196, 2019. 


\section{توصيف الآفات البؤرية الكبدية باستخدام خاصية الاسية الانتشار الموتر

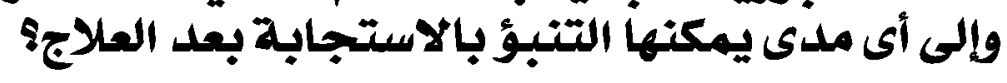

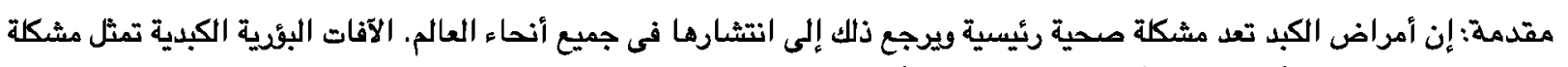

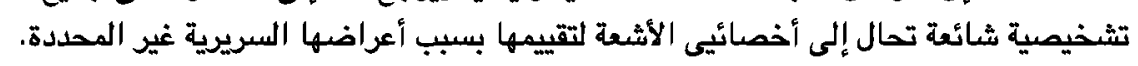

الهدف من الدراسة: تقييم دور الرنين المغناطيسى بخاصية الانتشار الموتر فى توصيف الآفات البؤدية الكبدية وتقييم مدى استجابتها للاعلاج.

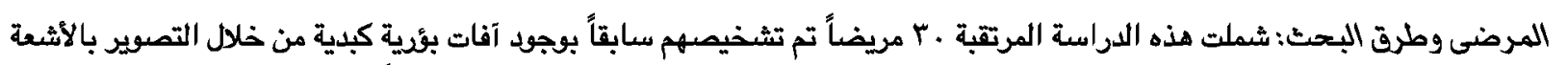

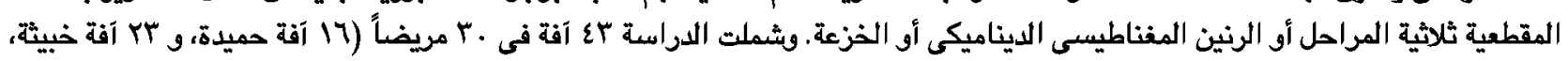

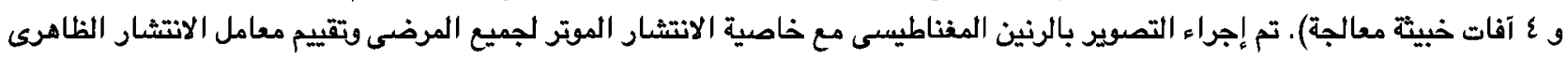
بالاضافة إلى معامل تفاوت الانكسار لجميع الآنات.

نتائج البحث: كان هناك فرق معتد به إحصائياً فى قيمة معامل الانتشار الظاهرى بين الآفات الحميدة والخبيثة وبين الآفات الخبيثة والخبيثة

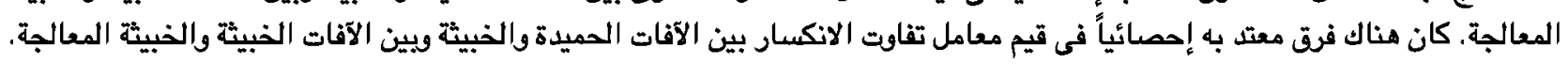

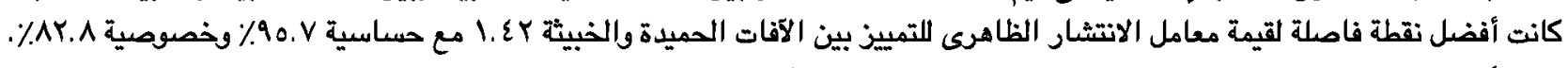

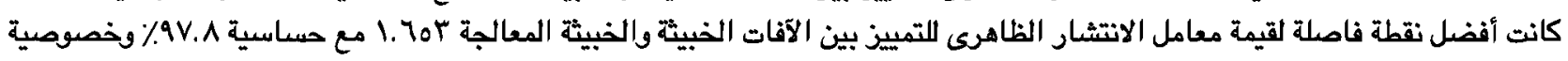

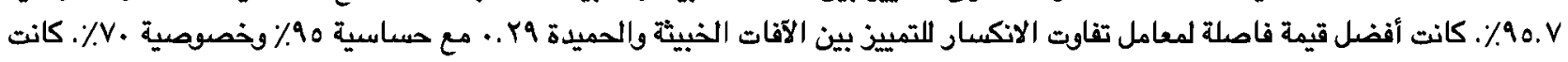

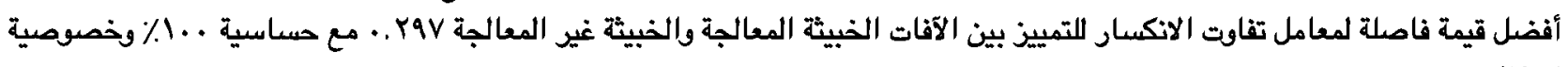

الإستتاج: تصوير الرنين المفناطيسى بخاصية الانتثار الموتر هو تقنية متطورة يمكن استخدامها لتوصيف الآفات البؤية الكبدية المختلفة

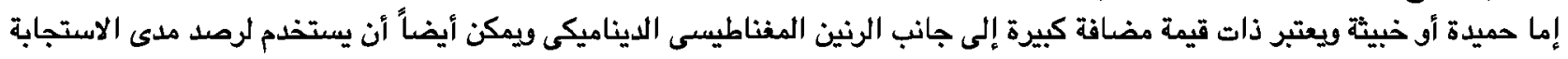
اللعلاج. 